\title{
Elaboración de un biodiente: enfoque actual y desafíos*
}

\author{
Making a Bio-tooth: Current Approaches and Challenges
}

Fecha de recepción: 16-04-2018 | Fecha de aceptación: 17-11-2018

\author{
Ruth ViViana Intriago Morales \\ Universidad de Cuenca. Cuenca, Ecuador. vivianaintriago_83@ hotmail.com. \\ https://orcid.org/0000-0002-4396-5617
}

\begin{abstract}
JOSÉ LUIS ÁLVAREZ VÁSQUEZ ${ }^{a}$
Universidad de Cuenca. Cuenca, Ecuador. jose.alvarezv@ucuenca.edu.ec. https://orcid.org/0000-

$\underline{0003-0381-2402}$
\end{abstract}

*Investigación original, revisión integrativa de la literatura.

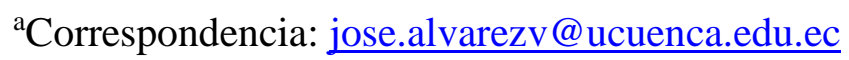

doi: https://doi.org/10.11144/Javeriana.uo37-79.ebea

Cómo citar: Intriago Morales RV, Álvarez Vásquez JL. Elaboración de un biodiente: enfoque actual y desafíos. Univ Odontol. 2018 jul-dic; 37(79). https://doi.org/10.11144/Javeriana.uo3779.ebea 


\section{RESUMEN}

Antecedentes: El edentulismo es uno de los mayores problemas de salud oral que cause alteraciones fisiológicas, sociales, estéticas, fonéticas y nutricionales. Las terapias actuales para el remplazo dental son artificiales y no satisfacen los requisitos básicos de un diente natural. La bioingeniería de tejidos constituye una alternativa para la sustitución de dientes perdidos. Objetivo: Identificar los enfoques/técnicas disponibles actualmente para obtener un diente completo por bioingeniería (biodiente), así como puntualizar sus desafíos y perspectivas futuras. Métodos: Se realizó una revisión integrativa de la literatura, por medio de las siguientes palabras clave: biodiente, bioingeniería de tejidos, diente entero y células madre. Los años de la búsqueda fueron 2000-2018, en las bases de datos: PubMed, Scopus, EBSCO, Science Direct, Wiley Online Library, Lilacs y Google Académico/Scholar, en inglés y español. Se seleccionaron únicamente artículos y libros de mayor relevancia y pertinencia. Resultados: Se obtuvieron 53 artículos y 10 libros. Para la elaboración de un biodiente se emplean los siguientes métodos: andamios, sin andamios, células madre pluripotentes inducidas, germen de órganos, diente quimérico y estimulación de la formación de la tercera dentición. El tamaño y forma normales del diente, así como la obtención de células epiteliales, son los principales desafíos. Conclusiones: La posibilidad de crear y desarrollar un biodiente en un ambiente oral adulto es cada vez más real gracias a los avances biotecnológicos que ocurren diariamente. Es posible que estos conceptos sean la base de la odontología restauradora en un futuro próximo.

\section{Palabras clave}


biodiente; bioingeniería dental; bio-raíz; células madre; ingeniería de tejidos; regeneración dental completa; odontología restauradora

\section{Áreas temáticas}

bioingeniería; endodoncia; medicina regenerativa; odontología

\section{ABSTRACT}

Background: Edentulism is one of the major oral health problems that cause physiological, social, aesthetic, phonetic, and nutritional issues. Current therapies for dental replacement are artificial and do not satisfy the basic requirements of a natural tooth. Tissue bioengineering could be a viable alternative to substitute lost teeth. Objective: To identify current available approaches/techniques to obtain a complete bioengineered tooth (bio-tooth) and to point out future challenges and perspectives. Methods: This was an integrative literature review. Search keywords used were: biotooth, tissue bioengineering, whole tooth, stem cells. The search included the years 2000 through 2018, using the databases PubMed, Scopus, EBSCO, Science Direct, Wiley Online Library, Lilacs and Google Scholar, both in English and Spanish. Only relevant and pertinent articles and books were selected. Results: 53 articles and 10 books were obtained. Methods for bio-tooth generation found were: scaffolds, scaffold-free, induced pluripotent stem cells, tooth organ germ, chimeric tooth, and stimulation of third dentition formation. Achieving normal tooth size and shape and obtaining epithelial cells are the main challenges. Conclusions: The possibility of creating and developing a whole bioengineered tooth (bio-tooth) in an adult oral environment is becoming more 
realistic, considering the daily biotechnological advances. It is possible that these concepts will be the basis of restorative dentistry in a near future.

\section{Keywords}

bio-root; bio-tooth; restorative dentistry; stem cells; tissue engineering; tooth bioengineering; whole tooth regeneration

\section{Thematic fields}

bioengineering; dentistry; endodontics; regenerative medicine

\section{INTRODUCCIÓN}

La pérdida de dientes es la insuficiencia de órganos más común, pues se estima que aproximadamente 158 millones de personas en todo el mundo la padecen (1), por lo tanto el edentulismo constituye un problema de salud relacionado con la aparición de enfermedades sistémicas al haber un deterioro de la función masticatoria (2), lo que ocasiona alteraciones fonéticas y estéticas, aspectos importantes para las interrelaciones sociales del individuo (1).

Actualmente, se siguen empleando procedimientos clínicos tradicionales para sustituir las estructuras dentarias, como prótesis fijas, removibles e implantes, los cuales utilizan materiales sintéticos o artificiales, disímiles a los dientes naturales en cuanto a las propiedades biológicas, físicas y mecánicas, pues no restauran íntegramente las funciones fisiológicas y en muchas ocasiones son incómodos para el paciente (1-5). Aunque los implantes dentales de titanio gozan 
de amplio uso en la actualidad, poseen las inherentes desventajas mencionadas, además de que varios pacientes tienen problemas con ellos durante o después de su colocación, como perimplantitis, pérdida ósea, recesión gingival e incluso eventual pérdida del implante $(6,7)$. Es por estos inconvenientes que se ha planteado un enfoque mucho más biológico para reemplazar las estructuras dentarias dañadas o perdidas, empleando dientes elaborados con técnicas de bioingeniería, también llamados biodientes $(4,5)$.

La formación de un diente es muy compleja y requiere la interacción recíproca y bien organizada entre el epitelio y el mesénquima, que deben tener la capacidad de proporcionar señales moleculares inductivas el uno al otro. Por lo tanto, es imperativo que se reproduzcan estos eventos para la generación in vitro de un diente entero de bioingeniería $(4,5,8,9)$.

Aunque se dispone en la literatura de información acerca de los métodos de bioingeniería de tejidos empleados para crear un biodiente, existe carencia de evidencia condensada y actual, esto es, que reúna todos los acercamientos o enfoques empleados, particularmente en el idioma español. Es por ello que la presente revisión aportará actualizando el estado del arte en el campo de la consecución de un biodiente mediante bioingeniería de tejidos.

El objetivo de esta revisión integrativa es describir los requisitos básicos para la obtención de un biodiente, identificar y contrastar los enfoques o técnicas disponibles para la obtención de este, así como describir sus desafíos y perspectivas futuras, para así aportar con fundamentos y conceptos para el desarrollo de futuras investigaciones que aporten con innovación en el campo de generación de un biodiente completo, y en general de la bioingeniería de tejidos dentales. 


\section{MATERIALES Y MÉTODOS}

El presente estudio es una revisión integrativa de la literatura, por lo que se incluyen en la misma estudios de tipo experimental y no experimental, con el fin de abordar diversos aspectos como conceptos, definiciones, metodologías y evidencia científica disponible (10). Se realizó una búsqueda electrónica de artículos científicos y libros que contengan la información requerida, empleando las bases de datos PubMed, Scopus, EBSCO, Science Direct, Wiley Online Library, Lilacs y Google Académico, tanto en idioma inglés como español. Los términos clave de búsqueda empleados en combinación fueron "bioingeniería dental", "ingeniería de tejidos", "regeneración dental completa", "células madre", "biodiente" y "bio-raíz". La estrategia de búsqueda fue específica para cada base de datos. Los términos relacionados fueron combinados usando los operadores “OR y “AND”. Se realizó la búsqueda desde enero del 2000 hasta marzo de 2018, excluyendo resultados fuera de este período de publicación. En la mayoría de los casos, los artículos que no tenían un vínculo explícito con los términos clave de búsqueda empleados, fueron eliminados. Luego, los resultados de la búsqueda fueron unidos, procediéndose a remover duplicados. Después de la selección inicial de títulos y resúmenes, se seleccionaron únicamente artículos y libros de mayor relevancia y pertinencia para el tema en revisión; los artículos fueron categorizados de acuerdo a las secciones de la presente revisión.

Por último, se estudió y analizó el texto completo de los 53 artículos seleccionados, así como la información pertinente de los 10 libros escogidos, con el fin de proveer a los lectores la más reciente y relevante información sobre la elaboración de un biodiente. Los contenidos a tratar serán 
abordados en tres grandes apartados: 1) Requisitos para la elaboración de un biodiente, 2) Enfoques utilizados en la generación de un biodiente, 3) Desafíos y perspectivas futuras en la elaboración de un biodiente.

\section{RESULTADOS}

\section{Requisitos para la elaboración de un biodiente}

El principal objetivo de la medicina regenerativa es desarrollar órganos de bioingeniería completamente funcionales para reemplazar órganos que se han perdido o dañado (11). Los enfoques para construir tejidos emplean una tríada básica de componentes: células madre, agentes bioactivos y andamios $(4,5,12)$.

\section{Células Madre}

En los últimos años se ha dado énfasis a la investigación con células madre ya que se ha demostrado su enorme potencial para promover la formación de tejidos como los dentarios $(5,13)$. Poseen habilidades de división continua, ya sea para replicarse a sí mismas, lo que se conoce como autorreplicación o para diferenciarse en células especializadas de varios linajes $(12,14,15)$.

Considerando el potencial de diferenciación, las células madre se clasifican en: totipotentes que son células embrionarias que pueden convertirse en cualquier tipo de célula del cuerpo; pluripotentes, que a diferencia de las anteriores no producen tejidos extraembionarios como la placenta; multipotentes cuyo potencial de diferenciación está más restringido y constituyen el grupo de células madre postnatales (16-18); oligopotentes que pueden diferenciarse en algunos 
tipos celulares de linaje específico; unipotentes, las cuales se diferencian únicamente en una clase de célula (18).

Dentro del campo de la medicina regenerativa se ha empleado dos tipos principales de células madre, las células madre embrionarias (ESC) y células madre postnatales, clasificación que obedece a su origen. La ausencia de ESC en una persona adulta y los problemas éticos concernientes a su uso hacen necesario la utilización de células madre postnatales de preferencia autólogas (obtenidas del propio paciente), sin embargo, deben superarse algunas dificultades inherentes a su aislamiento y diferenciación limitada, para que sea factible la aplicación en técnicas regenerativas (8).

En el contexto de las células madre postnatales, es posible aislar éstas células ya sea de tejidos dentarios o no dentarios; entre las fuentes potenciales de células madre mesenquimales de origen no dental se menciona a las células madre del tejido adiposo (ASCs) (19-21), las células madre de médula ósea (BMSCs). Como fuentes dentales de células madre mesenquimales tenemos aquellas que provienen de dientes maduros o inmaduros $(5,15,22)$, como las células madre que derivan de pulpa dental (DPSCs), células madre de dientes deciduos exfoliados (SHEDs), células madre del ligamento periodontal (PDLSCs), células madre de la papila apical (SCAPs), células madre del folículo dental (DFSCs), células madre progenitoras del germen dental (TGPCs), así como también células madre provenientes de otros tejidos orales y maxilofaciales, como células madre mesenquimales derivadas de encía (GMSCs), células madre del hueso orofacial (BMSCs), células madre del periostio (PSCs) y células madre derivadas de glándulas salivales (SGSCs); diferentes estudios han mostrado que estas células poseen gran potencial en la regeneración de tejidos 
dentales y periodontales (1,3,22-27). Dentro de la boca existen otras fuentes de células madre mesenquimales, como las células madre derivadas de mucosa oral (MSCs) y células madre del tejido conectivo palatal (MSCs) (22).

No existen fuentes consistentes de células madre epiteliales generadoras de esmalte en el humano adulto $(14,28)$ y probablemente este sea el factor limitante más importante en la elaboración de un biodiente $(15,29,30)$; sin embargo, actualmente se investiga arduamente estas posibles fuentes celulares. Así, ciertos tejidos orales postnatales podrían emplearse como fuente de células epiteliales, entre los que incluye células madre progenitoras del epitelio oral (OESCs); los restos epiteliales de Malassez (ERM) presentes en el ligamento periodontal (PDL) en la vaina epitelial radicular de Hertwig cerca de los extremos de una raíz en formación; en el epitelio reducido del esmalte (REE) que cubre el esmalte durante la erupción dental; el epitelio de unión (JE) a nivel del cuello dentario; la lámina dental activa (DL) que se encuentra en el área retromolar a los 5 o 6 años; los restos de la lámina dental del cordón gubernacular (GC), presentes por encima de los dientes en erupción (9).

El potencial proliferativo y odontogénico de éstas células epiteliales no se ha explorado del todo todavía y constituyen alternativas prometedoras para aplicarlas en la elaboración de un diente de bioingeniería (9). Se ha citado que los ERM pueden diferenciarse en células similares a ameloblastos cuando se combinan con células de papila dental, pudiendo ser una atractiva fuente celular para la regeneración del esmalte (31). 
También se ha demostrado que las células de la piel pueden diferenciarse en ameloblastos bajo la inducción del mesénquima. En un estudio en ratas se realizó la recombinación de células epiteliales cutáneas con células mesenquimales de la papila dental y tras la implantación por 14 días en la cápsula renal se observó la formación de estructuras similares a esmalte y dentina. Se comprobó que las células posnatales derivadas de la piel de ratas pueden convertirse en ameloblastos mediante una señalización apropiada del mesénquima dada por el factor de crecimiento fibroblástico 8 (FGF8) (32). Pese a que es un estudio realizado en animales, podría dar paso a la investigación en humanos con células cutáneas autólogas.

Entre las alternativas más llamativas para obtención de células madre epiteliales posnatales humanas para la regeneración de dientes enteros, se ha planteado el uso de queratinocitos aislados de prepucio humano, los mismos que se pueden diferenciar en ameloblastos bajo la inducción del mesénquima de ratón, demostrándose el potencial de estas células para la generación in vitro de un biodiente (33).

Por otro lado, es importante citar a las células madre pluripotentes inducidas (iPSCs), las cuales son generadas artificialmente a través de la manipulación genética de células somáticas y tienen el potencial de convertirse en cualquier tejido, como el dental $(1,34)$. Las iPSCs se pueden obtener a partir de células somáticas humanas mediante transducción retroviral de cuatro factores de transcripción Oct4/Sox2/Klf4/c-Myc o Lin28/Nanog/Oct4/Sox2, así como mediante técnicas libres de virus o ADN, llamadas no integradoras, basadas en ARNm o en proteínas recombinantes $(6,34,35)$. 
Las iPSCs tienen la ventaja de que son células autólogas, con lo que se evita preocupaciones éticas o de rechazo inmunológico, además son bastante accesibles y relativamente de fácil procesamiento (34). Su producción podría proporcionar una fuente ilimitada de células para aplicaciones clínicas, dejando atrás la ausencia de fuentes celulares, especialmente de las epiteliales $(13,29)$. Entre las desventajas del uso de las iPSCs se incluyen la memoria epigenética de su fenotipo anterior que limita su potencial de diferenciación, su naturaleza artificial, la transducción viral, las mutaciones somáticas, la tumorogénesis y la formación de teratomas, situaciones que deben ser superadas para su futuro uso clínico seguro $(34,36)$.

Se ha diseñado un modelo recombinante (29), donde se usan iPSCs derivadas de células de la orina humana que al contacto con mesénquima de ratón permite la obtención in vitro de células epiteliales dentales, modelo que luego al ser trasplantado bajo la cápsula renal de ratón deriva en la formación de un biodiente (figura 1). Por lo tanto, se puede considerar que la orina no es simplemente un desecho sino más bien constituye una fuente celular autóloga asequible, no invasiva, cómoda y que puede aplicarse a cualquier género, raza o edad; así, el sedimento de la orina posee células diferenciadas (epiteliales renales, uroteliales) y células madre (36). 
FIGURA 1

Biodientes formados en 3 semanas bajo la cápsula renal de ratón: A) a partir de células epiteliales y mesénquima de ratón y, B) a partir de células iPSCs obtenidas de orina humana y, mesénquima de ratón. En las dos columnas de la derecha se observan imágenes de los biodientes mediante microscopio de contraste de fase (MCF), fuera y bajo la cápsula renal. En las tres columnas de la izquierda se presentan cortes histológicos con tinción de hematoxilinaeosina (HE) y de inmunohistoquímica (IHC): pulpa dental (dp), dentina (d), espacio del esmalte (es), Amel (ameloblastina); en el recuadro azul de observan los ameloblastos
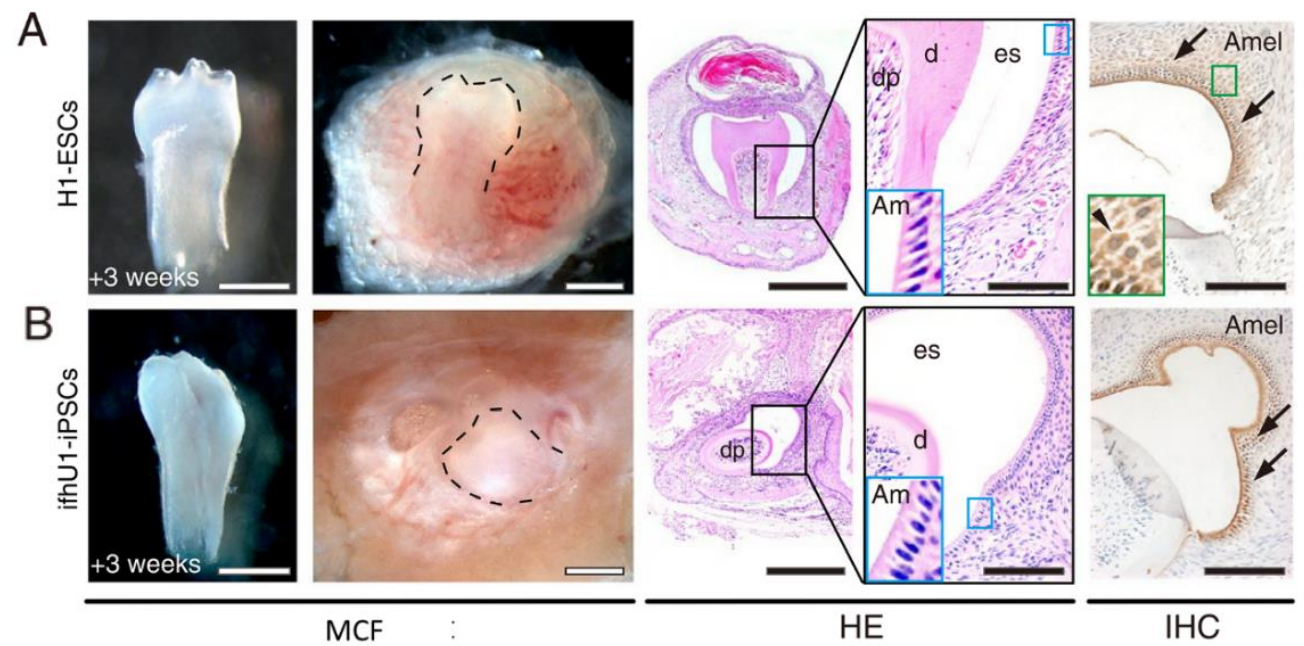

Tomado de: Cai J, Zhang Y, Liu P, Chen S, Wu X, Sun Y, Li A, Huang K, Luo R, Wang L, Liu Y, Zhou T, Wei S, Guangjin P, Duanqing P. Generation of tooth-like structures from integration-free human urine induced pluripotent stem cells. Cell Regen. 2013; 2: 6. (publicado con permiso de los autores)

Finalmente, en el contexto de las fuentes disponibles para la obtención de células madre, se debe puntualizar en este apartado que aquellas obtenidas de la orina humana $(29,36)$, al igual que las referidas células madre obtenidas de prepucio humano (33), ASCs obtenidas en procedimientos quirúrgicos como la liposucción (21), así como las células madre mesenquimales obtenidas de la pared de quistes periapicales dentales (37) y, células obtenidas de gérmenes dentales de animales de mataderos (38), todas ellas en conjunto están dentro del concepto moderno de medicina biológica del desecho (del inglés biological waste medicine), mediante el cual se puede obtener tejidos tan diversos como cardíaco, hepático, óseo, neuronal y dental, a partir de tejidos considerados como "desecho" (39), homologando un proceso de "reciclaje biológico" que inherentemente constituye un método de obtención celular totalmente no invasivo. 


\section{Agentes Bioactivos}

Todos los procesos biológicos del organismo están regulados por biomoléculas señalizadoras, también llamadas agentes bioactivos, como es el caso de la odontogénesis, cuyas fases están mediadas por una serie de interacciones entre epitelio y mesénquima, coordinando la migración, diferenciación, proliferación celular, expresión de genes, organización de tejidos y morfogénesis (4,5). Entre los agentes bioactivos están genes específicos, factores de crecimiento y de transcripción, que en ocasiones inducen el desarrollo y en otras lo inhiben $(40,41)$, actuando de manera muy coordinada en tiempo, lugar y cantidad precisa, a lo que se conoce como regulación espacio temporal (5). Al momento esta compleja expresión molecular no está del todo clara, aunque cada vez se entiende mejor, particularmente la participación génica (5). Entre algunos de los factores de crecimiento están el factor de crecimiento transformante beta (TGF $\beta$ ), la proteína morfogenética ósea (BMP), el factor de crecimiento fibroblástico (FGF), proteínas de las familias Wnt, Hedgehog (Shh) y Ectodisplasina (Eda) (41).

Para las terapias regenerativas los agentes bioactivos pueden incorporarse a los andamios, liberándose de forma explosiva durante las primeras horas, encapsulados en micro y nanopartículas cuya liberación es controlada o, quedar inmovilizados para que se liberen mientras se degrada la matriz. Actualmente se está desarrollando sistemas de liberación estímulo-respuesta basados en el $\mathrm{pH}$, temperatura, fuerza iónica, luz o impulsos eléctricos, con el fin de suministrar los agentes bioactivos al medio (5). 
Andamios (scaffolds)

Los andamios son esencialmente armazones de soporte, crean un microambiente odontogénico (24) que facilita la biosíntesis, proliferación y diferenciación celular (4). Este tipo de materiales deben cumplir ciertos requisitos como biocompatibilidad y biodegradabilidad, porosidad que permita la siembra, colonización y migración celular, la resistencia mecánica para facilitar su manipulación y la adaptación al sitio del defecto $(4,5)$.

Los andamios se clasifican en naturales y sintéticos. Entre los naturales se incluye el colágeno, el alginato, la fibrina, el quitosano, la gelatina, la seda, el ácido hialurónico, los mismos que son biocompatibles y biodegradables (5), pero sin embargo poseen propiedades mecánicas deficientes y podrían desencadenar respuestas inmunes negativas debido a la presencia de posibles impurezas dependiendo de su origen (42). Otra opción natural creada recientemente con el objetivo de reducir la inflamación, la reacción de cuerpo extraño y el potencial de rechazo inmunológico constituye el modelo de andamios descelularizados, en el cual se elimina los componentes celulares de tejidos u órganos por medio de procesos químicos, enzimáticos, o físicos, conservando la matriz extracelular (ECM). Estos andamios "biomiméticos" permiten la conservación de la estructura, la biocompatibilidad con el entorno, la estabilidad mecánica y facilitan la difusión de moléculas bioactivas, la interacción celular, la adhesión y la formación de ECM, por lo que se sugiere idealmente a esta tecnología para la generación de órganos de bioingeniería $(5,42,43)$.

Por otro lado, se dispone de andamios sintéticos, con limitaciones inherentes a la biodegradabilidad y biocompatibilidad, como el ácido poliglicólico (PGA), el ácido poliláctico (PLA), el ácido poliglicólico poli-L-láctico (PGA-PLLA), el ácido poliglicólico poliláctico 
(PLGA), la policaprolactona (PCL). También se han desarrollado materiales inorgánicos, tales como la cerámica de hidroxiapatita, las cerámicas de fosfato de calcio y los vidrios bioactivos $(1,5,44)$, e incluso se han diseñado andamios en micro y nanoescala, con el fin de replicar los eventos celulares que ocurren en estas escalas (5).

\section{Enfoques utilizados en la generación de un Biodiente}

Muy pocos han sido los estudios que han utilizado células humanas en la producción de dientes enteros de bioingeniería y, aunque la mayoría de éstos han tenido resultados exitosos al ser realizados en modelos animales, no obstante inherentemente representan una guía para establecer las estrategias básicas en la generación de biodientes en humanos para la terapia de reemplazo dental (1).

Los enfoques disponibles actualmente para la elaboración de un biodiente completo, son: métodos que utilizan andamios, métodos libres de andamios, método basado en el empleo de iPSCs, método del germen de órganos, el modelo de diente quimérico $(5,23,45-47)$ y la estimulación de la formación de la tercera dentición (48), los cuales serán descritos a continuación.

\section{Método basado en andamios}

En esta técnica de bioingeniería se emplea andamios, los cuales dan el soporte estructural a las células que posteriormente serán sembradas en el mismo. Las células epiteliales y mesenquimales son aisladas de brotes dentales postnatales de animales, luego son sembradas sobre andamios biodegradables y a continuación son trasplantadas a la cápsula suprarrenal, al omento o directamente al sitio de la exodoncia para su maduración in vivo (figura 2A) (49), demostrándose 
la formación de estructuras de dientes pequeños con tejidos como esmalte, dentina y pulpa dental (3). La desventaja más grande de este método es la incapacidad de controlar la forma y el tamaño de los dientes, así como la orientación de los ameloblastos y odontoblastos (49).

FIGURA 2

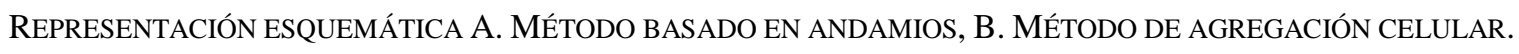

\section{A. Uso de Andamios}

Células progenitoras dentales

linaje mesenquimal

Formadoras (odontoblastos, células

de esmalte pulpares y periodontales)

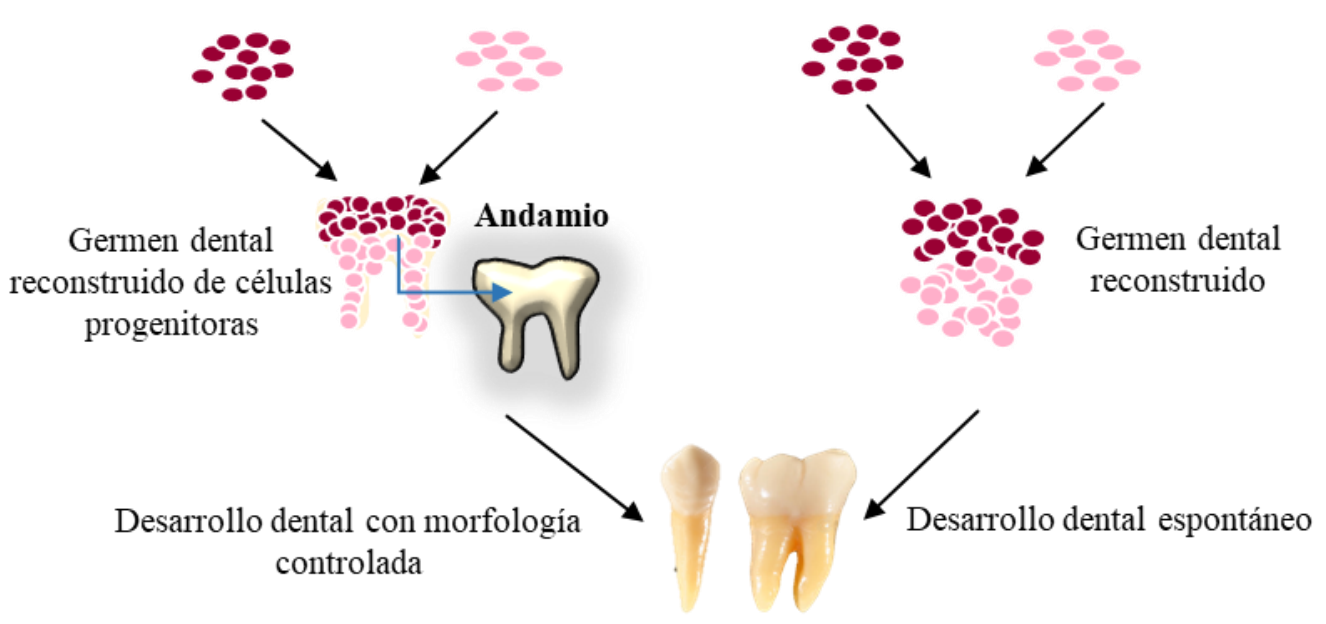

B. Método de agregación celular

Células derivadas de un germen dental

$$
\text { epiteliales mesenquimales }
$$

Recientemente se ha citado el empleo de andamios dentales descelularizados creados a partir de brotes dentarios porcinos sin erupcionar; luego se resembraron células epiteliales dentales porcinas, células de pulpa dental humana y células endoteliales de vena umbilical humana (proveyendo una red vascular), para luego implantar los constructos en las mandíbulas de minicerdos y cultivarlas por 3 o 6 meses. Tras el análisis histológico y con tomografía microcomputarizada $(\mu \mathrm{CT})$ se observó una producción significativa de dentina organizada y tejidos similares al esmalte, confirmándose el potencial de este tipo de tecnologías para el estudio de la formación de biodientes de tamaño semejante a los dientes naturales (38). 
Método libre de andamios

Denominado también método de agregación celular, este método produce gérmenes dentales de bioingeniería reconstruidos sin andamios, utilizando a su vez células epiteliales y mesenquimales obtenidas de gérmenes dentarios de modelos animales, a través de centrifugación. Las interacciones epitelio-mesénquima se reproducen correctamente por la capacidad de los agregados celulares de autorreorganizarse, lo que permite obtener biodientes, pero no obstante suele ser difícil controlar su desarrollo y formación tisular (figura 2B) $(3,47)$.

Un método libre de andamios es la técnica de gotas colgantes, de reciente introducción, la cual permite el cultivo de esferoides multicelulares en un medio líquido en 3D (GravityPLUS ${ }^{\mathrm{TM}}$ ). Los molares inferiores del ratón de día embrionario 14 (ED 14) se disociaron en células individuales epiteliales y mesenquimales, luego se sembraron en una placa de cultivo líquido que favoreció las migraciones celulares y al cabo de 3 días se formaron esferoides bien organizadas dentro ellas. Después de la implantación bajo la piel de ratones adultos por 2 semanas, se desarrollaron dientes vascularizados que tenían una corona bien formada, con esmalte, dentina y la iniciación de la formación radicular. Finalmente, y para propiciar la inervación del mesénquima dental, incluyendo la capa odontoblástica, se realizó un coimplante en el ganglio del trigémino. Este modelo puede reproducir las interacciones epitelio mesénquima que permiten un desarrollo óptimo de los dientes y una ventaja es el pequeño número de células que se requiere (50). 
Método basado en el empleo de iPSCs

Este constituye un método libre de andamios que utiliza únicamente iPSCs y es un modelo planteado en humanos, donde se induciría a las células somáticas (dentales o no dentales) para formar iPSCs, las cuales a su vez permitirían obtener tanto células madre epiteliales como mesenquimales con potencial odontogénico, que luego se recombinarían y en conjunto pasarían a cultivarse in vitro hasta la etapa de casquete y a continuación serían trasplantados los gérmenes dentales a los sitios edéntulos de los maxilares, para el reemplazo con dientes funcionales (figura 3) $(6,8,13,35)$. Este método tendría las ventajas antes ya referidas respecto a las iPSCs.

FIGURA 3

REPRESENTACIÓN ESQUEMÁTICA DEL MÉTODO BASADO EN EL EMPLEO DE IPSCS

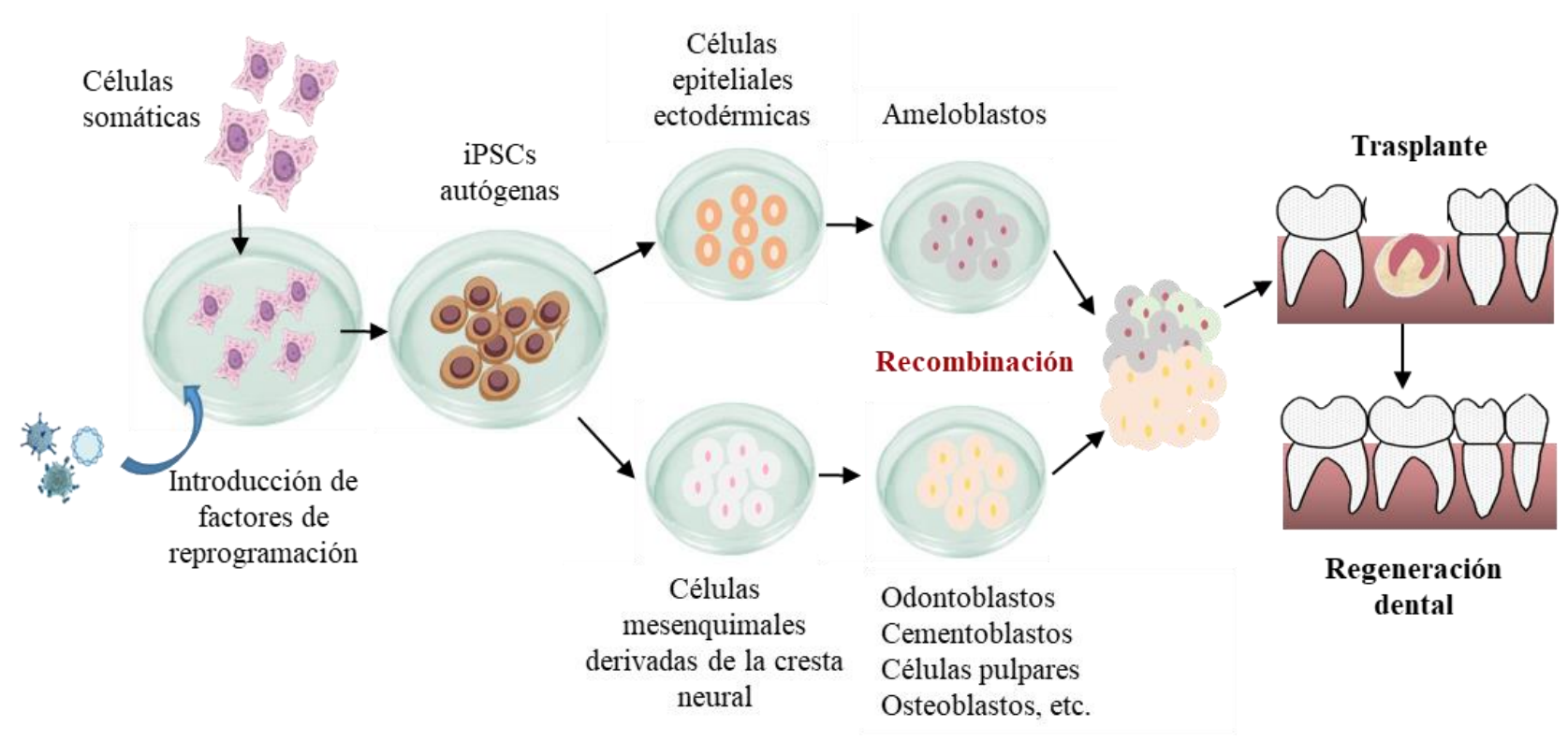

Método del germen de órganos

Es un enfoque de manipulación celular tridimensional in vitro que replica el proceso de odontogénesis, pues ocurre una compartimentación de las células epiteliales y mesenquimales 
dentro de un gel de colágeno de alta densidad, reproduciendo el montaje multicelular y las interacciones epitelio-mesénquima para desarrollar biodientes (51).

Con este modelo se puede obtener inicialmente gérmenes dentales que luego son trasplantados a una área edéntula de ratón (3), se consigue controlar exitosamente el tamaño del diente de bioingeniería, así como regular el ancho de la corona mediante el control de la zona de contacto entre el epitelio y las capas de células mesenquimales. Esta técnica ha permitido obtener incisivos (51) y molares de ratón (52).

En este método se inyectan células mesenquimáticas (aisladas de un germen molar de ratón) disociadas en el centro de una gota de colágeno de alta densidad. Se procede luego a la inyección de las células epiteliales derivadas del germen dental de un molar de ratón en una gota adyacente al agregado celular mesenquimal. Luego de un día de cultivo se observa la formación de un germen dental de bioingeniería con adecuada compartimentación entre las células epiteliales y mesenquimales y compactación célula a célula, el cual se desarrolla in vitro durante 14 días. Luego se realiza el trasplante de este germen dental bajo la cápsula renal por 30 días (figura 4A) (51,52).

$\mathrm{Al}$ cabo de este período se obtiene un biodiente maduro, con todos los componentes estructurales como esmalte, dentina, PDL y hueso alveolar bien formados (figura 4A). De la misma manera se puede obtener conjuntos de múltiples unidades de biodientes, rodeados de hueso alveolar, que pueden ser trasplantados para reparar grandes zonas edéntulas de los maxilares (figura 4B). Cabe destacar que los biodientes obtenidos mediante este método se injertaron en un ambiente adulto mediante unión ósea, esto es, a través de integración ósea del hueso del biodiente con el hueso 
maxilar. El biodiente alcanzó el plano oclusal en 49 días, realizando función masticatoria normal con el diente antagonista natural (52). Además, se observó la presencia de vasos sanguíneos y fibras nerviosas sensoriales y simpáticas, tanto en pulpa como $\operatorname{PDL}(51,52)$.

FIGURA 4

REPRESENTACIÓN ESQUEMÁTICA DEL MÉTODO DE GERMEN DE ÓRGANOS

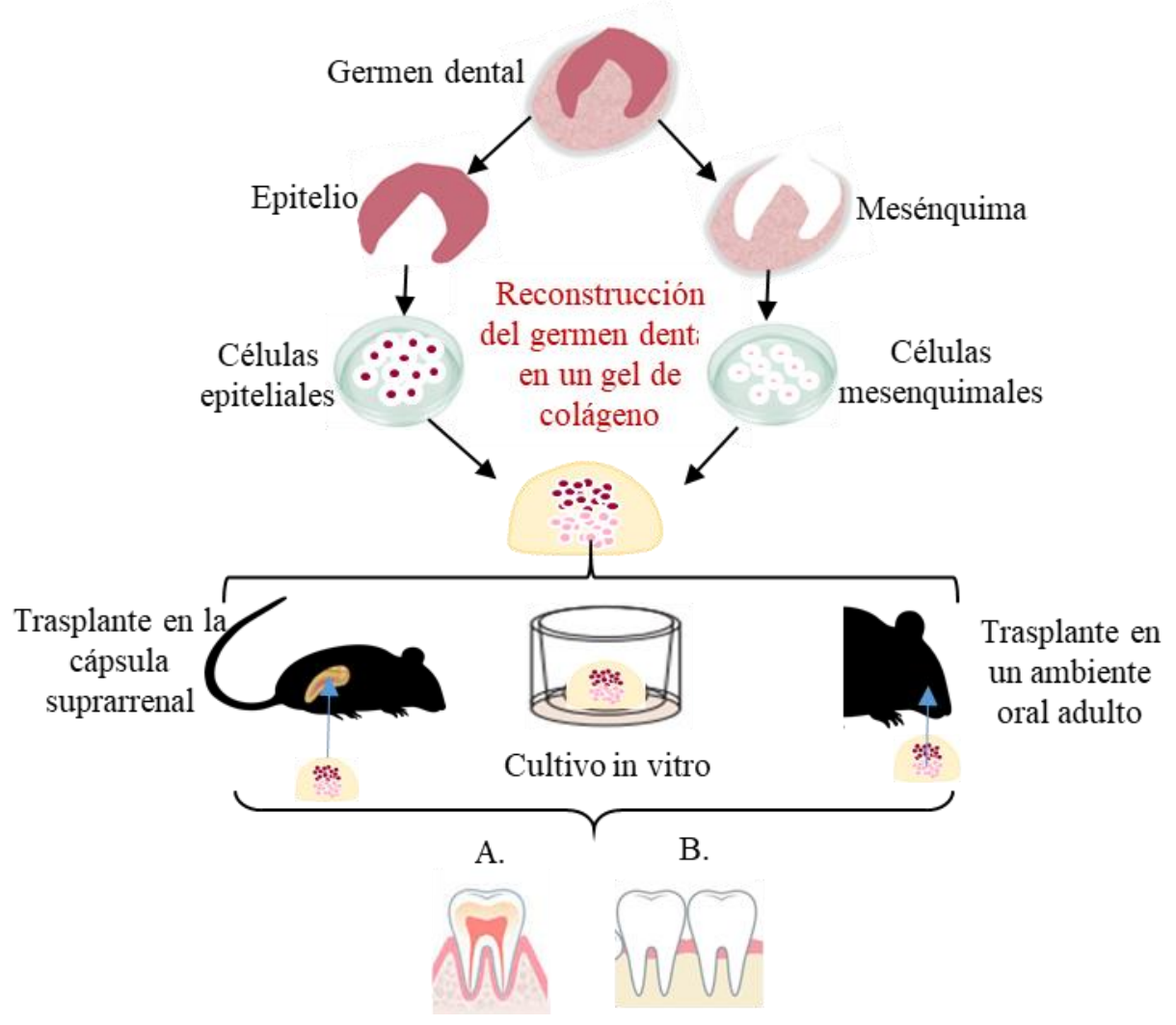

Es importante destacar que los biodientes obtenidos fueron sometidos a tratamiento de ortodoncia y expuestos a trauma por exposición pulpar, ante los cuales la respuesta neural fue completamente normal. Por otro lado, a estos biodientes se les aplicó pruebas de dureza de Knoop, dando como resultado valores similares al diente natural (52). 
Recientemente se ha desarrollado un nuevo enfoque denominado modelo biomimético del germen dental, en el cual empleando células dentales porcinas postnatales epiteliales y mesenquimales, células endoteliales de venas umbilicales humanas, así como hidrogel de gelatina metacrilato como andamio, se obtuvo in vitro gérmenes dentales bien conformados, los cuales fueron luego implantados de manera subcutánea en ratas inmunodeprimidas. Estos "constructos biomiméticos de gérmenes dentales en 3D", como lo denominan los autores, tenían todos los tejidos dentales y, fueron estudiados mediante imágenes de volumen de fuerzas, empleando el microscopio de fuerza atómica (AFM), con el fin de analizar los módulos de elasticidad de los tejidos dentales obtenidos, los cuales fueron similares a los del germen dental natural. Además, se monitoreó en 3D la morfología celular, actividad metabólica y formación de redes vasculares; éstas redes a futuro permitirían la integración y crecimiento in vivo del germen dental después de su trasplante al nicho óseo en humanos, como lo predicen los autores (7).

Diente quimérico o recombinante

El término quimera según la mitología griega describe a un monstruo híbrido con cuerpo de cabra, cola de serpiente o dragón y cabeza de león, que escupía fuego y aterrorizaba a la gente; sin embargo en la ciencia médica, una quimera es un organismo o un órgano que contiene poblaciones celulares procedentes de individuos genéticamente distintos, bien sean de la misma especie o de otra diferente (28).

Las investigaciones en quimeras se están enfocando en el campo del trasplante de órganos como corazón, hígado, riñón, piel y dientes. Con el fin de diseñar un biodiente quimérico DPSCs adultas 
humanas se han recombinado con células epiteliales dentales de otras especies como minicerdos y ratones, obteniéndose buenos resultados (28).

En un estudio, se diferenciaron iPSCs derivadas de la orina humana en células epiteliales dentales y, se recombinaron luego con el mesénquima de un molar de ratón. Tras 3 semanas de cultivo bajo la cápsula renal de ratones se observó la formación de un diente quimérico con propiedades físicas tales como el módulo de elasticidad y dureza similares a las del diente humano (figura 5); se comprobó el potencial de las iPSCs derivadas de la orina para dar origen a ameloblastos secretores de esmalte (29). Por otro lado, en un estudio aislaron y cultivaron queratinocitos obtenidos del prepucio humano, luego se recombinaron con el mesénquima dental aislado de un germen dental de ratón, en presencia de FGF8 exógeno y se observó la diferenciación en ameloblastos formadores de esmalte (33). Otros dos estudios también emplearon el modelo quimérico, los cuales ya fueron descritos anteriormente $(29,38)$.

FIGURA 5

REPRESENTACIÓN ESQUEMÁTICA DEL DIENTE QUIMÉRICO

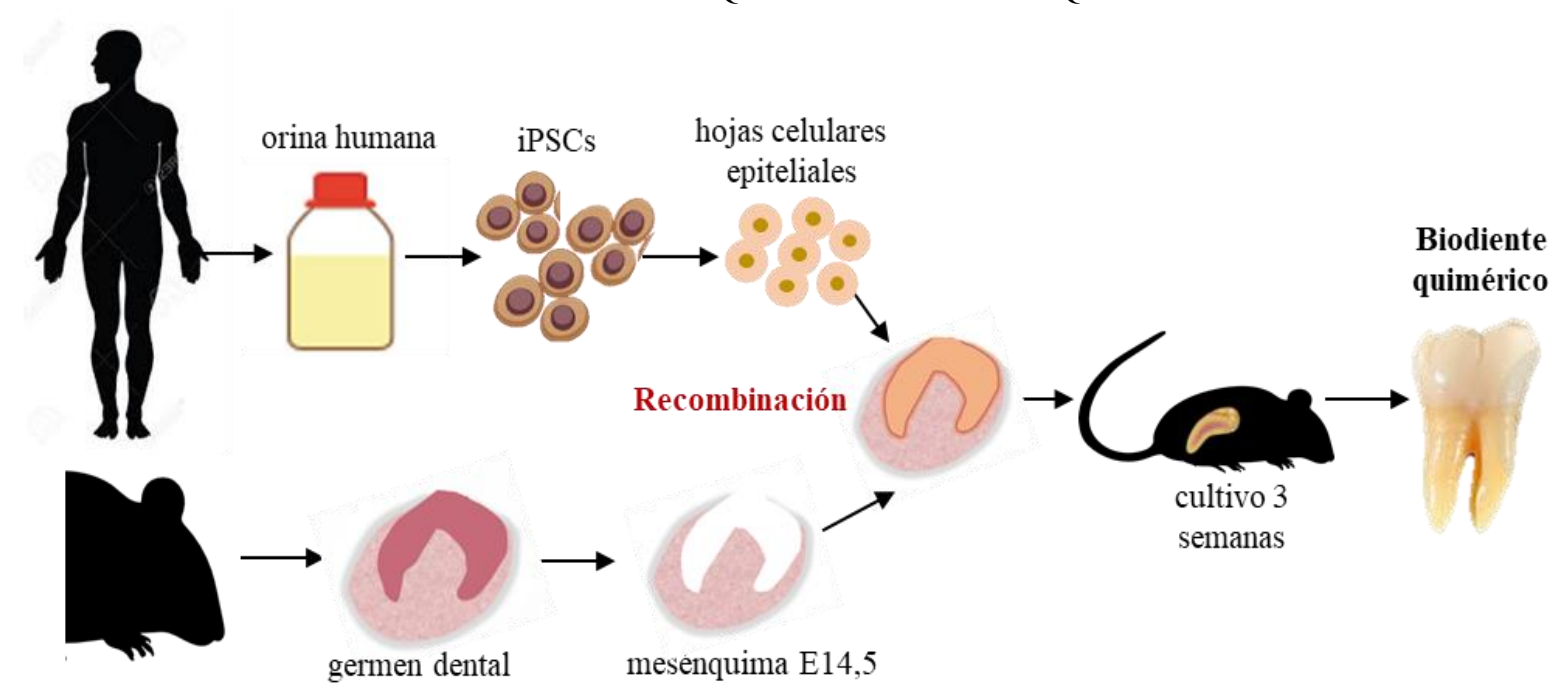


De la misma manera se creó dientes quiméricos derivados de células madre homólogas de diferentes individuos de la misma especie, donde se aislaron DPSCs de incisivos y BMSSCs de la médula ósea y se recombinaron con las células del brote apical $(\mathrm{ABC})$ de un germen de incisivo postnatal. Los conjuntos DPSC-ABC y BMSSC-ABC fueron incubados por 14 días in vivo y se formaron quimeras con estructuras dentarias típicas, pero en el grupo BMSSC-ABC no se llevó a cabo la formación de esmalte (53). Se requieren de investigaciones adicionales en este campo para la su futura aplicación clínica.

Método de estimulación de la tercera dentición

El término "tercera dentición" se refiere a un conjunto de dientes adicionales que pueden formarse además de los permanentes, es decir uno o más dientes supernumerarios. Durante la odontogénesis el número de dientes está estrictamente determinado, por lo que la manipulación de las vías moleculares puede inducir la formación de una tercera dentición $(48,54,55)$, cuyo rudimento se ha evidenciado en humanos (48).

La señalización Wnt está relacionada con la formación supernumeraria ya que interviene en el mantenimiento o la reactivación de la lámina dental (48) y se ha identificado que mutaciones en el gen Runx2 ocasionan la formación de dientes supernumerarios $(54,55)$, lo que podría constituir una vía para la inducción de formación de una tercera dentición mediante terapia génica. Por otro lado, en un modelo de ratón se ha demostrado que la inhibición de la señalización de BMP, modulada por Wnt, permite la formación de dientes supernumerarios en cultivos de incisivo. El gen 1 asociado a sensibilización uterina (USAG-1) controla la señalización de BMP y de Wnt; se ha informado que este gen es deficiente en ratones que tienen dientes supernumerarios, por lo que 
su represión in situ o activación podría ser una alternativa posible para inducir formación de nuevos dientes (48).

La terapia génica podría ser el medio ideal para suministrar moléculas de señalización, previamente identificadas en tiempo y espacio, que estimulen la formación de una tercera dentición y la regeneración de dientes manipulados con genes $(28,48)$. Con el fin de promover un efecto biológico específico se realiza la terapia génica (activación o represión), que consiste en la inserción de genes en las células de un individuo directamente en el sitio diana (in vivo), como ocurriría en el caso de la estimulación de una tercera dentición en humanos (figura 6), o indirectamente sobre células seleccionadas, cosechadas, expandidas, transducidas genéticamente (ex vivo), y luego reimplantarlas (48).

FIGURA 6

REPRESENTACIÓN ESQUEMÁTICA DEL MÉTODO DE ESTIMULACIÓN DE LA TERCERA DENTICIÓN.

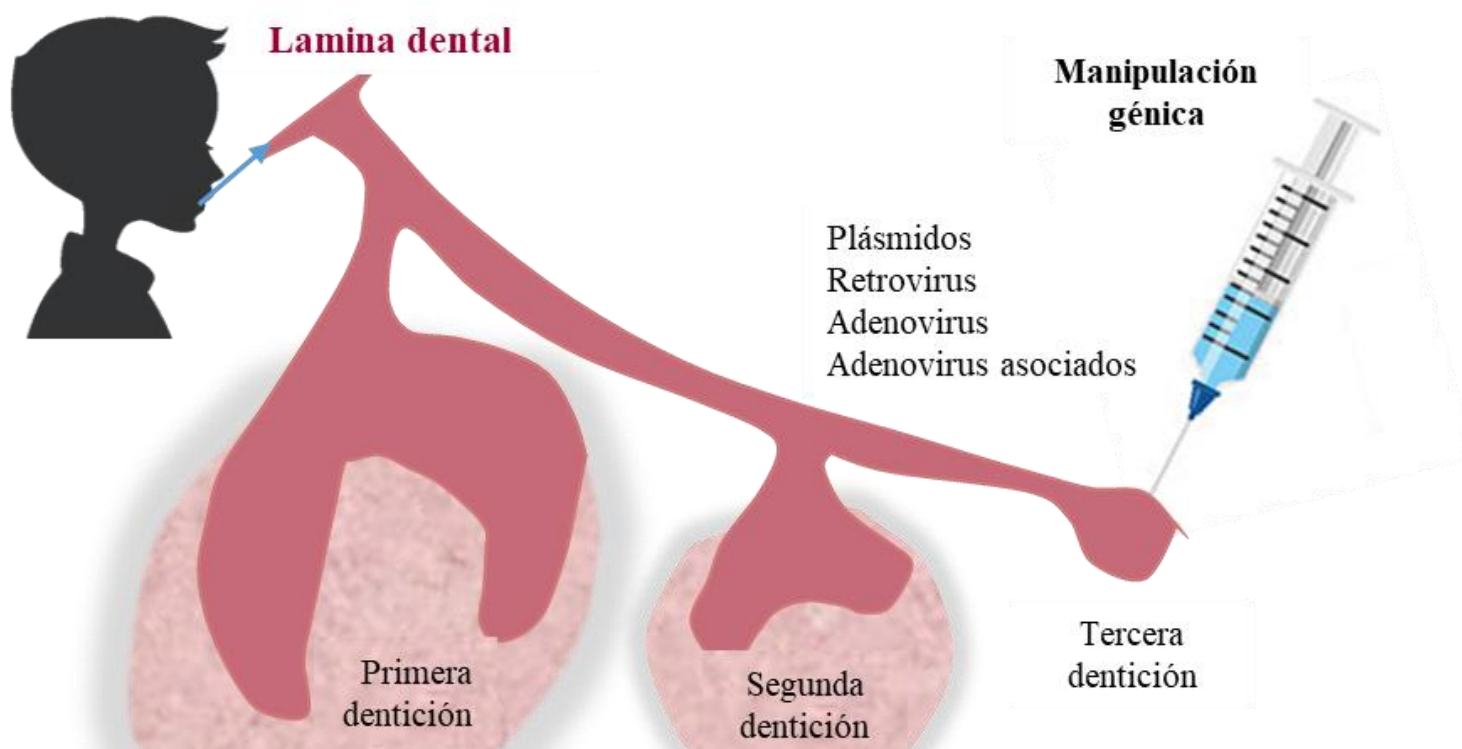


Hasta ahora, el suministro de genes in vivo parece ser viable para la regeneración de un diente mediante estimulación de la tercera dentición, con lo que se induciría nuevamente el proceso de dentición en la boca de la persona (48); sin embargo este enfoque ha sido cuestionado por posibles afectaciones sistémicas a la salud del individuo $(28,55)$.

\section{Bio-raíces}

El término "bio-raíz" se refiere a una raíz creada por bioingeniería, que puede estar perfectamente integrada con los tejidos periodontales y el hueso alveolar, sobre la cual sea posible colocar una corona $(3,15)$. La elaboración de una bio-raíz, pese a que no constituye un biodiente completo, podría ser una opción que solucione el problema de la regeneración del esmalte, ya que permitiría que una corona sintética sea soportada por una raíz de bioingeniería, considerando además que con los métodos protésicos actuales se puede reproducir perfectamente tamaño, forma y color de una corona natural $(27,30)$.

En un estudio reciente, se obtuvo bio-raíces en un modelo de minicerdo, mediante un sistema de cultivo 3D de células PDLSCs, DPSCs y de un injerto de (HA/TCP)/DPSC. Estas bio-raíces fueron rehabilitadas con coronas y postes 6 meses después de la implantación inicial y fueron comparadas in vivo con implantes de titanio igualmente rehabilitados, que fueron colocados en el mismo animal. Los estudios histológicos, radiográficos, biomecánicos y de microscopio electrónico de barrido, evidenciaron que la fuerza compresiva, módulo de elasticidad y fuerza torsional fueron muy similares a las del diente natural nativo; sin embargo, el implante de titanio mostró propiedades biomecánicas significativamente mayores que la bio-raíz, lo que pudo haber influido 
en la tasa de éxito del $100 \%$ y $22 \%$, respectivamente. Aunque resulta un modelo prometedor, la bio-raíz necesita más investigación antes de su aplicación clínica (56).

\section{Desafíos y perspectivas futuras en la elaboración de un biodiente}

Las limitadas fuentes de células madre epiteliales postnatales que generen esmalte constituye uno de los mayores desafíos, debido a que son difíciles de encontrar en ambientes adultos $(29,30,46)$. Sin embargo se están haciendo muchos adelantos al respecto y se proyecta el uso de algunos tejidos dentales o no dentales, los mismos que fueron descritos anteriormente, e inclusive de fuentes celulares de otras especies como posibles donantes $(13,28,47)$.

El control exacto de la forma y el tamaño del biodiente se vuelve difícil tomando en cuenta que el diente debe tener una oclusión y función masticatoria normal y que las morfologías de todos los grupos dentarios son complejas de reproducir con bioingeniería (28). También, será un reto replicar con el biodiente las características mecánicas y de anisotropía del diente nativo perdido (5).

El conocimiento de la regulación molecular de los agentes bioactivos de señalización y de los genes involucrados en el desarrollo de un diente, al momento no está del todo dilucidado, pero si se llega a comprender y controlar este aspecto espacio temporalmente y cuantitativamente, ello facilitaría de manera significativa la recreación de todos los eventos de la odontogénesis y la consecución de un biodiente $(5,27,28)$. 
El rechazo inmunológico al biodiente trasplantado generalmente es causado por un grupo de antígenos conocido como el complejo mayor de histocompatibilidad (MHC), que reaccionan ante la presencia de tejidos injertados no idénticos a los de la persona, destruyéndolos rápidamente. De ahí que es importante que los tejidos de bioingeniería se realicen con células autólogas $(13,28)$.

El crecimiento del biodiente en los maxilares se considera un limitante debido a la dificultad de imitar las condiciones locales. Básicamente, los tejidos dentarios de bioingeniería se pueden incubar in vitro, in situ (ortotópicamente) y, heterotópicamente, es decir en hábitats temporales para su crecimiento, como el ectodermo embrionario de pollo, el área subcutánea, el epiplón (omento), mesenterio, la cápsula renal, o la cámara anterior del ojo en cerdos o ratas; sin embargo, estos sitios no reproducen exactamente el escenario de los maxilares $(28,47)$.

La erupción del biodiente en los maxilares también es difícil de replicar, ya que la erupción dental es un proceso gobernado por el folículo dental y el órgano del esmalte. Así mismo, conseguir que el biodiente llegue a una posición oclusal correcta es uno de los retos más importantes en los que se debe trabajar en humanos $(28,46)$.

Conseguir una adecuada vascularización es uno de los grandes desafíos asociados a la consecución de un diente de bioingeniería tanto en modelos in vitro como in vivo, sobre lo cual se debe seguir trabajando $(5,47)$, aunque los avances en este sentido han sido satisfactorios con algunos modelos de bioingeniería dental $(7,38,50,57)$. 
Obtener una óptima inervación del biodiente es otro reto a conseguir, lo cual ha sido ya evidenciado con el modelo de germen de órganos (3), así como en estudios de membrana de policaprolactona funcionalizada con factor de crecimiento neural $(57,58)$. Esta inervación del biodiente permitiría la percepción neuronal ante estímulos nocivos y fisiológicos (51).

Aunque el proceso de implantación y erupción de los biodientes toma pocas semanas en modelos animales como el ratón, hay que considerar que el proceso de desarrollo dental en humanos toma varios años. De ahí que otro importante desafío será conseguir acelerar este proceso para poder lograr su aplicación clínica en tiempos “aceptables” (6,27).

Las iPSCs se proyectan como fuente promisoria de obtención tanto de células epiteliales como mesenquimales para la terapia dental regenerativa, incluyendo el biodiente $\quad(13,34,35,46)$, aunque quedan por superarse muchos aspectos relacionados con su seguridad, eficacia y costo (6). Así mismo, el modelo de germen de órganos parece prometedor para la consecución del biodiente en humanos $(3,46,52,59)$.

Una vez que se pruebe su éxito en humanos, el biodiente deberá aún superar obstáculos inherentes a su complejidad para avanzar hacia su producción a escala comercial, mediante biorreactores por ejemplo (los cuales permiten alcanzar y mantener condiciones ambientales específicas), y asíllegar a su aplicación clínica, asegurando que los pacientes se beneficien de los avances científicos (35). En este contexto, se podría pensar que en un futuro los bancos de células alogénicas permitirán acceder a la bioingeniería dental a un costo de fabricación significativamente más bajo que la producción de células autólogas $(27,35)$. 
Un método promisorio en rápida evolución es el modelo de impresión en 3D para generación de andamios, en la cual se deposita capa por capa el material hasta obtener el tamaño y forma deseados $(1,44)$. Aunque este método permite conseguir réplicas espaciales únicas e incluso posicionamiento celular, todavía tiene retos que superar como su elevado costo, incrementar la resolución y velocidad de impresión en 3D $(60,61)$.

\section{DISCUSIÓN}

La presente revisión integrativa de la literatura permitió identificar y describir los diversos enfoques con los que se dispone actualmente para la elaboración de un diente completo de bioingeniería. Se podría considerar que la identificación de las células madre en pulpa dental humana en el año 2000 (25), marcó el inicio de una serie de estudios dedicados a la bioingeniería de tejidos dentales, algunos de los cuales han sido justamente incluidos en la presente revisión y, han ido introduciendo técnicas cada vez más complejas, pero que no obstante están precisamente encaminando las investigaciones hacia a la consecución final de un biodiente integrado a la boca de un ser humano.

De todos los enfoques antes referidos, al parecer uno de los métodos más promisorios es el basado en iPSCs, especialmente si se considera que con él se pueden emplear células autólogas y/o células consideradas como "desecho biológico", en tanto que el enfoque de estimulación de la tercera dentición podría ser el que más desafíos y retos tiene que superar, no obstante, inherentemente todos los enfoques tienen dificultades técnicas y éticas que deben ser aún solventadas. 
En el contexto de búsqueda de evidencia para la elaboración de la presente revisión, llama la atención que en la literatura en español existe una carencia de estudios experimentales para la elaboración de un biodiente, lo cual podría obedecer a las dificultades técnicas y económicas presentes en Latinoamérica. Uno de los estudios que se puede mencionar es uno realizado con ratas Lewis, con el que se obtuvieron constructos tridimensionales de tejidos semejantes a dientes (62).

Es importante destacar que en el año el 2006 un equipo de científicos expertos en el tema se congregó con la visión de idear un plan para la creación de un biodiente, que crezca independientemente in vivo en un adulto humano. Plantearon que este objetivo podría ser conseguido en un período de diez años, es decir para el año 2017 (63). Probablemente los desafíos antes mencionados son bastante difíciles de superar por completo, por lo que al momento todavía no se ha podido cumplir con aquel reto, pero es increíble el avance que la ciencia ha tenido al respecto, por lo que no debería sorprendernos que se superen estos desafíos y que en las próximas generaciones de la Odontología ya se cuente con dientes de bioingeniería totalmente funcionales e integrados en un entorno oral adulto y con esto reemplazar de forma natural estructuras dentarias pérdidas o ausentes.

\section{CONCLUSIONES}

El reemplazo biológico de los dientes perdidos por dientes formados por bioingeniería de tejidos permitiría superar las deficiencias de los actuales tratamientos de reemplazo o sustitución de 
dientes naturales, como los implantes de titanio de difundido uso en la actualidad. La elaboración de bio-raíces y su posterior rehabilitación con coronas, es tal vez a un futuro mediato una alternativa más factible que la elaboración de un diente entero de bioingeniería, que tiene que superar mayores dificultades en su ejecución.

Finalmente, pese a los retos y desafíos existentes al momento en la elaboración de un diente de bioingeniería, la ciencia ha tenido grandes progresos en los últimos años, que hacen cada vez más real la posibilidad de la ejecución de un biodiente humano, completo, funcional y totalmente integrado a los tejidos circundantes. Este concepto representaría la base para las próximas generaciones de la Odontología, relegando a varias de las terapéuticas tradicionales usadas durante décadas para el mantenimiento o reemplazo dental.

\section{RECOMENDACIONES}

Se debe seguir explorando la identificación de células madre epiteliales y mesenquimales que puedan ser mantenidas y expandidas en cultivos in vitro, con el fin de proveer suficientes fuentes para la elaboración de dientes de bioingeniería.

La comprensión de la señalización biomolecular y expresión génica facilitaría en gran medida la reproducción de todos los eventos de la odontogénesis, para conseguir la formación de tejidos y órganos dentarios enteros de bioingeniería. Este conocimiento podría además ir mejorando o complementando las diferentes técnicas disponibles, por lo que se recomienda se realicen estudios en esta temática. 
A pesar de los avances de la terapia génica in vivo, que podría enriquecer las técnicas de bioingeniería dental e incluso estimular la formación de una tercera dentición, se requiere más investigaciones al respecto.

El desarrollo de biomateriales de andamio óptimos para modular adecuadamente el proceso de la odontogénesis es esencial en el campo de la medicina regenerativa, siendo una opción atractiva ampliar las investigaciones respecto a los andamios descelularizados por sus características superiores en relación a los otros andamios. Además, el diseño de andamios en micro y nanoescala es prometedor y requiere estudios adicionales.

Es necesario que se realicen estudios adicionales en modelos animales y de esta manera dar el paso a la realización de ensayos clínicos en humanos, en los que se utilice células autólogas o alogénicas, o incluso dar paso al empleo clínico del diente quimérico.

Una vez que se solventen las desventajas concernientes al uso de las iPSCs, estas células podrían ser idóneas para la elaboración de un biodiente, ante la carencia de ESC en personas adultas y considerando todas las ventajas y características de las iPSCs.

Incentivar la ejecución de estudios de bioingeniería de tejidos basados en el concepto de "medicina del desecho", sobre todo considerando el hecho de que ésta representa una fuente celular muy asequible y que se desperdicia a diario. 


\section{REFERENCIAS}

1. Smith EE, Yelick PC. Progress in bioengineered whole tooth research: from bench to dental patient chair. Curr Oral Health Rep. 2016 Dec; 3(4): 302-8.

2. Howard M. Innovaciones en Odontología: la regeneración de los tejidos dentales y el reemplazo biológico de los dientes. Rev Científica Odontológica. 2012 Sep; 6(1).

3. Oshima M, Tsuji T. Functional tooth regenerative therapy: tooth tissue regeneration and whole-tooth replacement. Odontology. 2014 Jul; 102(2): 123-36.

4. Yadav P, Tahir M, Yadav H, Sureka R, Garg A. Test tube tooth: the next big thing. J Clin Diagn Res. 2016 Jun; 10(6): ZE01-3.

5. Monteiro N, Yelick PC. Advances and perspectives in tooth tissue engineering. J Tissue Eng Regen Med. 2016 Jan; 11(9): 2443-61.

6. Liu P, Zhang Y, Chen S, Cai J, Pei D. Application of iPS cells in dental bioengineering and beyond. Stem Cell Rev Rep. 2014 Oct; 10(5): 663-70.

7. Smith EE, Zhang W, Schiele NR, Khademhosseini A, Kuo CK, Yelick PC. Developing a biomimetic tooth bud model. J Tissue Eng Regen Med. 2017 Dec; 11(12): 3326-36.

8. Zhang Y, Chen Y. Bioengineering of a human whole tooth: progress and challenge. Cell Regen. 2014 Apr; 3(1): 8.

9. Padma Priya S, Higuchi A, Abu Fanas S, Pooi Ling M, Kumari Neela V, Sunil PM, Saraswathi TR, Murugan K, Alarfaj AA, Munusamy MA, Kumar S. Odontogenic epithelial stem cells: hidden sources. Lab Invest. 2015 Dec; 95(12): 1344-52.

10. Whittemore R, Knafl K. The integrative review: updated methodology. J Adv Nurs. 2005 Dec; 52(5): 546-53. 
11. Wang Y, Preston B, Guan G. Tooth bioengineering leads the next generation of dentistry. Int J Paediatr Dent. 2012 Nov; 22(6): 406-18.

12. Alvarez J. Ingeniería de tejidos en endodoncia: estado actual e implicaciones futuras. Odontociencia: Facultad de Odontología, Universidad de Cuenca. 2010 Jul; 2(7): 13.

13. Otsu K, Kumakami-Sakano M, Fujiwara N, Kikuchi K, Keller L, Lesot H, Harada H. Stem cell sources for tooth regeneration: current status and future prospects. Front Physiol. 2014 Feb; 5(36).

14. Céspedes D, Perona G. Futuro de la odontología restauradora. Rev Estomatológica Hered. 2014 Ago; 20(1): 44.

15. Jucht D, Rujano R, Romero M, Rondón L. Utilización de células madre en el ámbito odontológico. Revisión de la literatura. Acta Bioclínica. 2014 Oct; 0(0): 101-23.

16. Zeidán-Chuliá F, Noda M. “Opening” the mesenchymal stem cell tool box. Eur J Dent. 2009 Jul; 3(3): 240-9.

17. Saber SE-DM. Tissue engineering in endodontics. J Oral Sci. 2009 Dec; 51(4): 495-507.

18. Singh R, Gaikwad S, Chatterjee S, Ray P. Stem cells: the holy grail of regenerative medicine. In: Engineering in translational medicine. London: Springer-Verlag; 2014.

19. Argentati C, Morena F, Bazzucchi M, Armentano I, Emiliani C, Martino S. Adipose stem cell translational applications: from bench-to-bedside: Cartilage tissue engineering. Vol. 19. 2018.

20. Frese L, Dijkman PE, Hoerstrup SP. Adipose tissue-derived stem cells in regenerative medicine. Transfus Med Hemother. 2016 Jul; 43(4): 268-74.

21. Mahmoudifar N, Doran PM. Mesenchymal stem cells derived from human adipose tissue. Methods Mol Biol Clifton NJ. 2015; 13(40): 53-64. 
22. Hakki SS, Karaoz E. Dental stem cells: Possibility for generation of a Bio-tooth. In: Dental Stem Cells. Springer International Publishing; 2016.167-96.

23. Caicedo C-J, Villareal M-P. Avances en bioingeniería dental y su aplicación en ortodoncia y ortopedia dentofacial: Una revisión de literatura. Rev Estomatol. 2017 Jul; 25(1).

24. Yan M, Yu Y, Zhang G, Tang C, Yu J. A journey from dental pulp stem cells to a bio-tooth. Stem Cell Rev. 2011 Mar; 7(1): 161-71.

25. Gronthos S, Mankani M, Brahim J, Robey PG, Shi S. Postnatal human dental pulp stem cells (DPSCs) in vitro and in vivo. Proc Natl Acad Sci U S A. 2000 Dec; 97(25): 13625-30.

26. Egusa H, Sonoyama W, Nishimura M, Atsuta I, Akiyama K. Stem cells in dentistry--part I: stem cell sources. J Prosthodont Res. 2012 Jul; 56(3): 151-65.

27. Volponi AA, Pang Y, Sharpe PT. Stem cell-based biological tooth repair and regeneration. Trends Cell Biol. 2010 Dec; 20-206(12-6): 715-22.

28. Yu J, Shi J, Jin Y. Current approaches and challenges in making a bio-tooth. Tissue Eng Part B Rev. 2008 Sep; 14(3): 307-19.

29. Cai J, Zhang Y, Liu P, Chen S, Wu X, Sun Y, Li A, Huang K, Luo R, Wang L, Liu Y, Zhou T, Wei S, Guangjin P, Duanqing P. Generation of tooth-like structures from integration-free human urine induced pluripotent stem cells. Cell Regen. 2013 Jul; 2(1): 6.

30. Lymperi S, Ligoudistianou C, Taraslia V, Kontakiotis E, Anastasiadou E. Dental Stem Cells and their Applications in Dental Tissue Engineering. Open Dent J. 2013 Jul; 7:76-81.

31. Shinmura Y, Tsuchiya S, Hata K-I, Honda MJ. Quiescent epithelial cell rests of Malassez can differentiate into ameloblast-like cells. J Cell Physiol. 2008 Dec; 217(3): 728-38. 
32. Liu Y, Jiang M, Hao W, Liu W, Tang L, Liu H, Jin Y. Skin epithelial cells as possible substitutes for ameloblasts during tooth regeneration. J Tissue Eng Regen Med. 2013 Dec; 7(12): 934-43.

33. Wang B, Li L, Du S, Liu C, Lin X, Chen Y, Zhang Y. Induction of human keratinocytes into enamel-secreting ameloblasts. Dev Biol. 2010 Aug; 344(2): 795-9.

34. Malhotra N. Induced Pluripotent Stem (iPS) Cells in Dentistry: A Review. Int J Stem Cells. 2016 Nov; 9(2): 176-85.

35. Waddington R, Sloan A. Tissue engineering and regeneration in dentistry. Willey-Blackwell; 2017.

36. Benda C, Zhou T, Wang X, Tian W, Grillari J, Tse H-F, Grillari-Voglauer R, Pei D, Esteban M. Urine as a source of stem cells. In: Mesenchymal stem cells - basics and clinical application I. Springer Berlin Heidelberg; 2012.19-32.

37. Marrelli M, Paduano F, Tatullo M. Cells isolated from human periapical cysts express mesenchymal stem cell-like properties. Int J Biol Sci. 2013 Nov; 9(10): 1070-8.

38. Zhang W, Vazquez B, Oreadi D, Yelick PC. Decellularized tooth bud scaffolds for tooth regeneration. J Dent Res. 2017 May; 96(5): 516-23.

39. Marelli M, Paduano F, Rengo C, Spagnuolo G, Rengo S, Tatullo M. The human periapical cyst-mesenchymal stem cells (hPCy-MSCs): the new challenge of "waste medicine" in regenerative dentistry. In: MSCs and innovative biomaterials in dentistry. Humana Press; 2017.

40. Wang X-P, Suomalainen M, Jorgez CJ, Matzuk MM, Werner S, Thesleff I. Follistatin regulates enamel patterning in mouse incisors by asymmetrically inhibiting BMP signaling and ameloblast differentiation. Dev Cell. 2004 Nov; 7(5): 719-30. 
41. Zhang YD, Chen Z, Song YQ, Liu C, Chen YP. Making a tooth: growth factors, transcription factors, and stem cells. Cell Res. 2005 May; 15(5): 301-16.

42. Wolfe P, Sell S, Bowlin G. Natural and synthetic scaffolds. In: Tissue engineering: from lab to clinic. Berlin Heidelberg: Springer-Verlag; 2011.

43. Taylor DA, Sampaio LC, Ferdous Z, Gobin AS, Taite LJ. Decellularized matrices in regenerative medicine. Acta Biomater. 2018 Jul; 74: 74-89.

44. Zhang L, Morsi Y, Wang Y, Li Y, Ramakrishna S. Review scaffold design and stem cells for tooth regeneration. Jpn Dent Sci Rev. 2013 Feb; 49(1): 14-26.

45. Romero Jasso G, Barrios A, C B. Bioingeniería dental, ¿El futuro de la terapia en odontología? Rev Asoc Dent Mex. 2011 Jul; 68(4): 169-74.

46. Tsuji $\mathrm{T}$, editor. Functional tooth regeneration. In: Organ Regeneration Based on Developmental Biology. Springer Singapore; 2017.

47. Steindorff MM, Lehl H, Winkel A, Stiesch M. Innovative approaches to regenerate teeth by tissue engineering. Arch Oral Biol. 2014 Feb; 59(2): 158-66.

48. Takahashi K, Kiso H, Saito K, Togo Y, Tsukamoto H, Huang B, Bessho K. Feasibility of gene therapy for tooth regeneration by stimulation of a third dentition. In: Gene therapy tools and potential applications. 2013.

49. Bhanja A, D'Souza DSJ. Mapping the milestones in tooth regeneration: Current trends and future research. Med J Armed Forces India. 2016 Dec; 72, Supplement 1:S24-30.

50. Kuchler-Bopp S, Bécavin T, Kökten T, Weickert JL, Keller L, Lesot H, Deveaux E, Benkirane-Jessel N. Three-dimensional micro-culture system for Tooth tissue engineering. J Dent Res. 2016 Jun 1; 95(6): 657-64. 
51. Nakao K, Morita R, Saji Y, Ishida K, Tomita Y, Ogawa M, Saitoh M, Tomooka Y, Tsuji T. The development of a bioengineered organ germ method. Nat Methods. 2007 Mar; 4(3): 22730.

52. Ikeda E, Morita R, Nakao K, Ishida K, Nakamura T, Takano-Yamamoto T, Ogawa M, Mizuno M, Kasugai S, Tsuji T. Fully functional bioengineered tooth replacement as an organ replacement therapy. Proc Natl Acad Sci U S A. 2009 Aug; 106(32): 13475-80.

53. Yu J, Wang Y, Deng Z, Tang L, Li Y, Shi J, Jin Y. Odontogenic capability: bone marrow stromal stem cells versus dental pulp stem cells. Biol Cell. 2007 Aug; 99(8): 465-74.

54. Koussoulakou DS, Margaritis LH, Koussoulakos SL. A curriculum vitae of teeth: evolution, generation, regeneration. Int J Biol Sci. 2009 Feb; 5(3): 226-43.

55. Sartaj R, Sharpe P. Biological tooth replacement. J Anat. 2006 Oct; 209(4): 503-9.

56. Gao ZH, Hu L, Liu GL, Wei FL, Liu Y, Liu ZH, Fan ZP, Zhang CM, Wang J, Wang S. Bioroot and implant-based restoration as a tooth replacement alternative. J Dent Res. 2016 Jun; 95(6): 642-9.

57. Eap S, Bécavin T, Keller L, Kökten T, Fioretti F, Weickert J-L, Deveaux E, Benkirane-Jessel N, Kuchler-Bopp S. Nanofibers implant functionalized by neural growth factor as a strategy to innervate a bioengineered tooth. Adv Healthc Mater. 2014 Mar; 3(3): 386-91.

58. Kuchler-Bopp S, Larrea A, Petry L, Idoux-Gillet Y, Sebastian V, Ferrandon A, Schwinté P, Arruebo M, Benkirane-Jessel N. Promoting bioengineered tooth innervation using nanostructured and hybrid scaffolds. Acta Biomater. 2017 Mar; 50: 493-501.

59. Oshima M, Tsuji T. Whole tooth regeneration as a future dental treatment. In: Engineering Mineralized and Load Bearing Tissues. Springer International Publishing; 2015. 255-69. 
60. Kačarević ŽP, Rider PM, Alkildani S, Retnasingh S, Smeets R, Jung O, Ivanišević Z, Barbeck M. An nntroduction to 3D bioprinting: possibilities, challenges and future aspects. Mater Basel Switz. 2018 Nov; 11(11).

61. Malkoc V. Challenges and the future of 3D bioprinting. J Biomed Imaging Bioeng. 2018; 2(1).

62. Jaramillo L. Síntesis y evaluación histológica de constructos tridimensionales que promueven la interacción de células mesenquimales con ectodermo oral embrionario de ratas Lewis para la obtención de tejidos semejantes a dientes. Pontificia Universidad Javeriana, Colombia; 2012.

63. Snead ML. Whole-tooth regeneration: It takes a village of scientists, clinicians, and patients. J Dent Educ. 2008 Jan; 72(8): 903-11. 